Revta brasil. Bot., São Paulo, V.23, n.1, p.97-106, mar. 2000

\title{
Florística e estrutura de três trechos de uma floresta semidecídua na Estação Ecológica do Tripuí, Ouro Preto, MG
}

\author{
MÁRCIO DE SOUZA WERNECK ${ }^{1}$, GILBERTO PEDRALLI ${ }^{2,3}$, ROSSANA KOENIG $^{2}$ e \\ LETÍCIA FARAH GISEKE ${ }^{2}$
}

(recebido em 20 de janeiro de 1999; aceito em 15 de dezembro de 1999)

\begin{abstract}
Floristic and structure of three sites of semideciduous forest in the Tripuí Ecological Station, Ouro Preto, MG). The purpose of this study was to describe the floristic composition and structural changes in three sites of the arboreal community of a semideciduous forest in the Tripuí Ecological Station (EET), located in Ouro Preto, Minas Gerais State, Brazil. Sites one (A1) and two (A2) are the most conserved patches, without any disturbance reported during the last 30 years. Site three (A3) is the youngest successional portion of this forest and it occurs in an old area of tea plantation abandoned for 40 years. In each site, every tree with perimeter at breast height $(\mathrm{PBH}) \geq 5 \mathrm{~cm}$ found in three quadrats of $10 \times 30 \mathrm{~m}$ was sampled. The soils in the EET were considered structurally young, with low fertility. Sixty eight species of trees belonging to 42 genera and 25 families were registered. The most representative families in number of species were Myrtaceae (13), Lauraceae (9), Fabaceae (5), Flacourtiaceae (5) and Rubiaceae (5). The distribution of $\mathrm{PBH}$ and height classes of $\mathrm{A} 1$ and $\mathrm{A} 2$ are significantly different from A3. The Shannon index was higher in A1 (3.15), followed by A3 (3.00) and A2 (2.36). Sorensen index showed a low floristic similarity among the three sites studied. The floristic and structural differences found in the forest studied are due to differences in the intensity of human interference in the past.
\end{abstract}

RESUMO - (Florística e estrutura de três trechos de uma floresta semidecídua na Estação Ecológica do Tripuí, Ouro Preto, MG). O presente estudo foi desenvolvido em três trechos de floresta semidecídua, que no passado tiveram usos diferenciados, localizados na Estação Ecológica do Tripuí (EET), Ouro Preto (MG), objetivando verificar as variações qualitativas e equantitativas das espécies arbóreas. As áreas 1 (A1) e 2 (A2) representam os trechos mais preservados da floresta, não havendo relatos de perturbação, como fogo ou retirada de madeira, nos últimos 30 anos. A área 3 (A3) representa o trecho sucessional mais jovem da floresta, onde houve uma antiga plantação de chá preto, abandonada há 40 anos. Foram demarcadas, em cada trecho, três parcelas de 10 × $30 \mathrm{~m}$, onde foram amostrados todos os indivíduos vivos com perímetro a altura do peito (PAP) $\geq 5 \mathrm{~cm}$. Os solos na EET foram considerados estruturalmente jovens e de baixa fertilidade. Encontrou-se um total de 68 espécies, pertencentes a 42 gêneros, representando 25 famílias. As famílias mais representativas em número de espécies foram Myrtaceae (13), Lauraceae (9), Fabaceae (5), Flacourtiaceae (5) e Rubiaceae (5). Nos trechos de floresta A1 e A2, a distribuição em classes de PAP e de altura foram significativamente diferentes da verificada no trecho A3. O índice de Shannon foi maior em A1 $(3,15)$, seguido de A3 $(3,00)$ e de A2 $(2,36)$. Observou-se uma baixa similaridade florística, pelo índice de Sorensen, entre os três trechos estudados. As diferenças florísticas e estruturais encontradas devem-se, principalmente, às diferentes intensidades de pressão antrópica a que os trechos foram submetidos no passado.

Key words - Floristic, structure, semideciduous forest, Tripuí Ecological Station

\section{Introdução}

1. Departamento de Botânica, Universidade Federal de Minas Gerais, Caixa Postal 486, 30161-970 Belo Horizonte, MG, Brasil.

2. Setor de Recursos da Terra, Fundação Centro Tecnológico de Minas Gerais, Av. José Cândido da Silveira, 2000, 31170-000 Belo Horizonte, MG, Brasil.

3. Autor para correspondência: pedralli@ cetec.br
Em Minas Gerais, as fisionomias florestais se estendiam por uma vasta região do centro-sul e leste do estado (IBGE 1993). Da mesma forma como ocorreu em vários outros estados brasileiros, onde o processo de ocupação e exploração remonta ao período colonial, a cobertura florestal primitiva desta região de Minas Gerais foi reduzida a remanescentes esparsos, sendo que a maioria encontra-se ou bas- 
tante perturbada pela retirada seletiva de madeira ou situada em áreas onde a topografia dificulta o acesso (Oliveira-Filho \& Machado 1993).

As florestas semidecíduas ocorrem na forma de manchas, principalmente na região do cerrado do Brasil central (Rizzini 1997) e já ocuparam uma área bastante expressiva ao longo de Minas Gerais (Leitão-Filho 1982). Essas florestas apresentam uma alta diversidade florística e possuem uma flora arbórea bem estudada, quando comparada com a de outras formações vegetais (Leitão-Filho 1992). Apesar da consciência crescente sobre a importância destes recursos florestais e da necessidade de conservá-los, poucos são os estudos sobre a composição florística e estrutura fitossociológica destas florestas no estado de Minas Gerais, podendo-se citar como mais significativos os de Oliveira-Filho \& Machado (1993), Oliveira-Filho et al. (1994), Vilela et al. (1994), Araújo \& Haridassan (1997), Araújo et al. (1997), Pedralli \& Teixeira (1997) e Pedralli et al. (1997). Esses trabalhos e outros desenvolvidos na região sudeste têm demonstrado a existência de diferenças significativas na composição florística e na estrutura de remanescentes localizados em áreas relativamente próximas.

Os estudos detalhados sobre a composição florística e a ecologia das comunidades vegetais são fundamentais para embasar quaisquer iniciativas de preservação e conservação de remanescentes florestais (Oliveira-Filho et al. 1994), bem como para o desenvolvimento de modelos de recuperação de áreas degradadas, para a seleção de espécies para fins silviculturais e para a utilização racional dos recursos vegetais através do manejo adequado.

O presente trabalho teve por objetivos verificar as variações qualitativas e quantitativas das espécies arbóreas encontradas em três trechos de uma floresta semidecídua, com diferentes intensidades de uso no passado, na Estação Ecológica do Tripuí.

\section{Material e métodos}

A Estação Ecológica do Tripuí (EET) situa-se no município de Ouro Preto, na zona metalúrgica de Minas Gerais (20²3'45'S e 4334'33'W), na sub-bacia do córrego Tripuí (figura 1). Possui uma área de 337 ha, com níveis altimétricos variando entre 1280 e $1450 \mathrm{~m}$, solos litólicos de natureza álica e textura areno-siltosa. O clima é do tipo Cwb, subtropical moderado úmido, com precipi- tações abundantes no verão (médias de 1450 a $1800 \mathrm{~mm}$ ) e temperaturas frias, com uma média anual variando entre 17 e $18,5^{\circ} \mathrm{C}$. A EET representa uma das poucas áreas destinadas à preservação de Peripatus acacioi Marcus \& Marcus 1955 (Onychophora), que é considerado um "elo perdido" entre os anelídeos e os artrópodos (FEAM 1995).

Para a análise qualitativa e quantitativa do estrato arbóreo, foram selecionados três trechos que representassem as diferentes fisionomias dentro da floresta semidecídua. A área 1 - "Repolheiro" (A1) representa o trecho mais preservado da floresta, não havendo relatos de perturbação, como fogo ou retirada de madeira, nos últimos 30 anos. Na área 2 - "Macacos" (A2) a floresta apresenta fisionomia intermediária entre A1 e A3 (figura 1), não havendo relatos de perturbação nos últimos 30 anos. A área 3 - "Chá" (A3) representa o trecho sucessional mais jovem da floresta e ocorre em local onde havia uma antiga plantação de chá preto (Camellia sinensis (L.) Kuntze), abandonada há pelo menos 40 anos.

Para a caracterização pedológica do solo, nas áreas de amostragem, foram realizadas observações pontuais, através de tradagens sumárias, precedidas de coletas de amostras superficiais $(0-20 \mathrm{~cm})$, submetidas às análises de granulometria, $\mathrm{pH}$ em $\mathrm{H}_{2} \mathrm{O}$, matéria orgânica, $\mathrm{C}, \mathrm{Al}^{3+}$, $\mathrm{Ca}^{2+}, \mathrm{Mg}^{2+}$ e $\mathrm{K}^{+}$, realizadas no laboratório do Instituto Mineiro de Agropecuária, segundo metodologia proposta por Lemos \& Santos (1984). Para a classificação taxonômica e fases de relevo, usaram-se as normas, critérios e nomenclatura citados em Camargo et al. (1987).

O método de parcelas (Mueller-Dombois \& Ellenberg 1974) foi empregado para a obtenção dos dados florísticos e estruturais, demarcando-se, em cada área, um módulo amostral de 10 × 30 m, subdividido em parcelas de $10 \times 10 \mathrm{~m}$, onde foram amostrados todos os indivíduos lenhosos com PAP (perímetro à altura do peito) $\geq 5 \mathrm{~cm}$. $\mathrm{O}$ material vegetal coletado no período de março de 1997 a agosto de 1998, foi herborizado segundo as técnicas convencionais (Mori et al. 1989), e incorporado ao Herbário HXBH do Setor de Recursos da Terra (SAT) da Fundação Centro Tecnológico de Minas Gerais (CETEC). As identificações foram realizadas por meio de consultas à literatura e especialistas, além de comparações com as coleções do Herbário citado e dos Herbários da Universidade Federal de Minas Gerais (Herbário BHCB) e da Universidade de São Paulo (Herbário SPF).

Para a caracterização estrutural dos três trechos estudados, foram elaborados histogramas de freqüência de classes de perímetro e de altura de todas as árvores vivas amostradas. As diferenças na distribuição dos indivíduos em classes de perímetro e de altura, entre os trechos estudados, foram analisadas através do teste de Kolmogorov-Smirnov (Sokal \& Rholf 1979). Calculou-se, também, os índices de diversidade de Shannon (H') e a 
equabilidade (J) correspondente (Krebs 1989), para os três trechos e utilizou-se o índice de similaridade de Sorensen (Mueller-Dombois \& Ellenberg 1974), para a análise da similaridade entre áreas.

\section{Resultados e Discussão}

Os solos na EET são desenvolvidos sobre material litólico, atribuído ao grupo Minas, formados essencialmente, por xistos, filitos e, bem menos fre- qüentemente, por quartzitos. Ocorrem em relevo muito movimentado (forte ondulado e montanhoso), com declividades dominantes quase sempre superiores a $25 \%$, atingindo muitas vezes mais de $45 \%$, apresentando caráter raso (Solos Litólicos) ou pouco a medianamente profundos (Cambissolos), com presença de minerais primários facilmente intemperizáveis. A fertilidade é muito baixa, devido aos reduzidos teores de $\mathrm{Ca}^{2+}, \mathrm{Mg}^{2+}$ e $\mathrm{K}^{+}$, apresentando

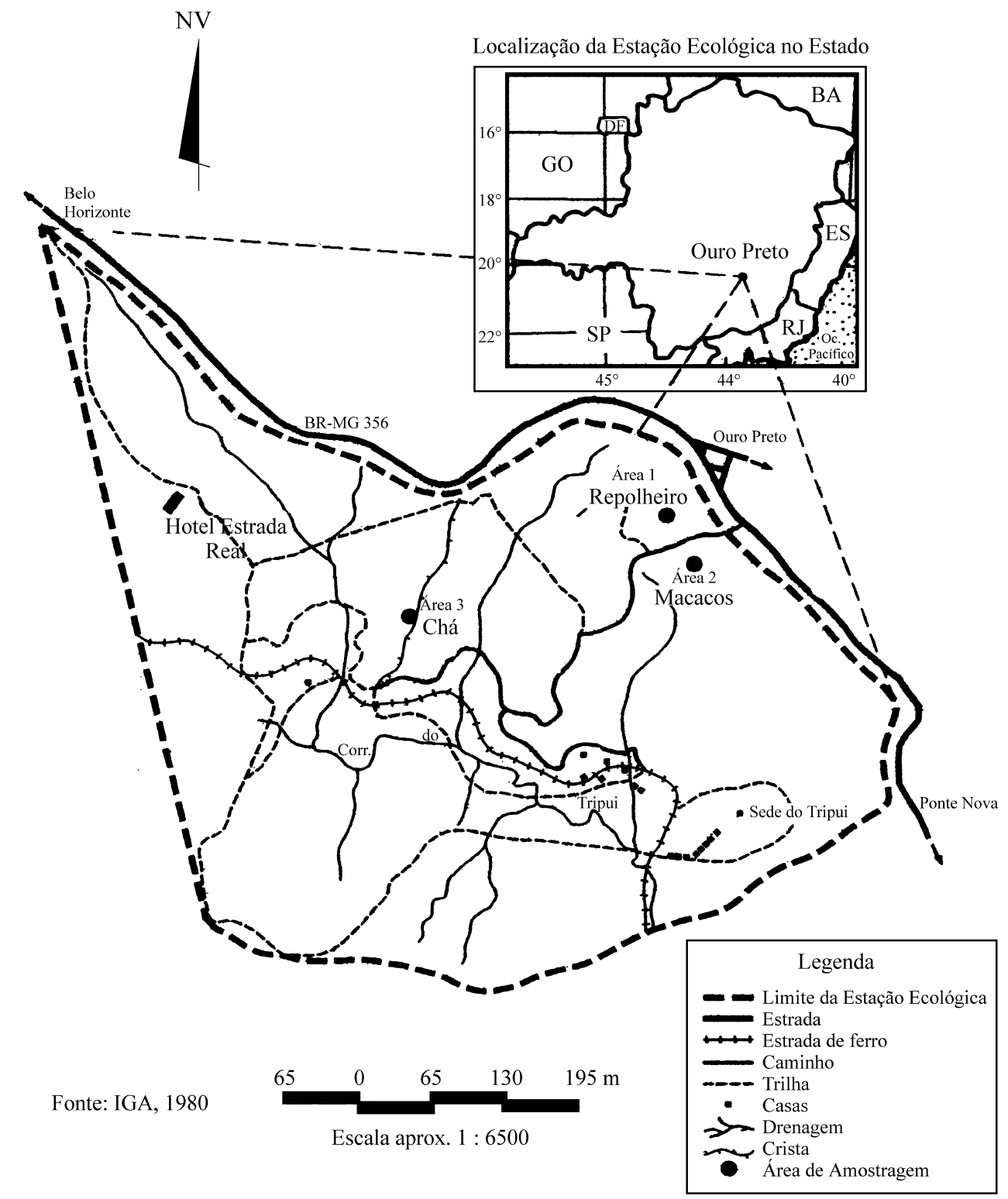

Figura 1. Localização da Estação Ecológica do Tripuí, em Ouro Preto (MG), e disposição dos três trechos amostrais. 
elevada acidez devido ao excesso de $\mathrm{Al}^{3+}$, não havendo diferenças edáficas significativas entre as áreas estudadas (tabela 1). A composição granulométrica de amostras superficiais $(0-20 \mathrm{~cm})$ revelou o predomínio de texturas médias, características de solos incipientes (tabela 1), sugerindo que os solos da floresta semidecídua na EET podem ser considerados jovens em termos estruturais. Estes dados, somados às observações de campo, permitem classificar os solos em: S1 - Solo Cambissolo Álico A moderado, textura média, relevo forte ondulado/montanhoso; S2 - Solo Cambissolo Álico A moderado, textura média, relevo ondulado/forte ondulado e S3 - Solo Litólico Álico A moderado, textura arenosa, relevo forte ondulado.

Identificou-se, nos três trechos, um total de 68 espécies, pertencentes a 42 gêneros, representando 25 famílias (tabela 2). As famílias com maior riqueza específica foram Myrtaceae (13), Lauraceae (9), Fabaceae (5), Flacourtiaceae (5) e Rubiaceae (5), sendo que Myrtaceae, Lauraceae, Rubiaceae e Fabaceae, possuíram também os maiores valores de abundância (tabela 2), dados similares aos citados para florestas semidecíduas na região sudeste por Rodrigues et al. (1989), Grombone et al. (1990), Gandolfi et al. (1995), Pagano et al. (1995) e no estado de Minas Gerais por Oliveira-Filho \& Machado (1993), Oliveira-Filho et al. (1994), Vilela et al. (1994), Araújo
\& Haridassan (1997), Araújo et al. (1997), Pedralli et al. (1997) e Pedralli \& Teixeira (1997). Outras famílias apresentaram poucas espécies, porém muito abundantes, como é o caso de Anacardiaceae, Annonaceae e Myrsinaceae (tabela 2). Os gêneros Myrcia e Ocotea destacaram-se pelo maior número de espécies (4), seguidos por Casearia, Guatteria, Machaerium e Nectandra, com três espécies, Dalbergia, Eugenia, Gomidesia, Maytenus, Miconia, Mollinedia, Psychotria, Solanum e Xylosma com duas espécies, estando os demais 27 gêneros $(64,3 \%)$ representados por uma única espécie.

Peixoto e Gentry (1990), afirmaram que Myrtaceae assume uma grande importância ecológica nas florestas da costa atlântica do Brasil, onde é encontrada com grande riqueza de espécies e abundância. Segundo Pinto \& Oliveira-Filho (1999), as famílias Myrtaceae, Lauraceae e Melastomataceae pendem para um vínculo florístico mais forte com a Província Atlântica (sensu Cabrera \& Willink 1973), enquanto Fabaceae e Annonaceae são importantes na Província Atlântica e na Amazônica (sensu Cabrera \& Willink 1973). A grande diversidade de Lauraceae e Rubiaceae evidencia laços florísticos com a Floresta Ombrófila Mista Alto-Montana (Veloso et al. 1992). Contudo, não se pode afirmar, conclusivamente, se a floresta semidecídua da EET apresenta ou não um vínculo florístico com a Provín-

Tabela 1. Análise química e granulométrica do solo dos três trechos de floresta estudados (A1, A2 e A3) na Estação Ecológica do Tripuí, Ouro Preto, MG. Os valores são média \pm desvio-padrão.

\begin{tabular}{|c|c|c|c|}
\hline Parâmetro & A1 & $\mathrm{A} 2$ & A3 \\
\hline Areia grossa (dag/kg) & $11,00 \pm 0,00$ & $7,00 \pm 1,00$ & $11,67 \pm 2,08$ \\
\hline Areia fina $(\mathrm{dag} / \mathrm{kg})$ & $45,67 \pm 4,04$ & $36,33 \pm 2,08$ & $63,67 \pm 3,21$ \\
\hline Silte (dag/kg) & $25,67 \pm 5,51$ & $31,67 \pm 4,73$ & $14,33 \pm 2,08$ \\
\hline Argila (dag/kg) & $17,67 \pm 1,53$ & $25,00 \pm 6,56$ & $10,33 \pm 3,21$ \\
\hline pH em água & $4,10 \pm 0,17$ & $4,70 \pm 0,10$ & $4,43 \pm 0,21$ \\
\hline Matéria orgânica (dag/kg) & $5,66 \pm 0,86$ & $5,85 \pm 0,58$ & $4,54 \pm 0,84$ \\
\hline $\mathrm{C}(\mathrm{dag} / \mathrm{kg})$ & $3,28 \pm 0,50$ & $3,40 \pm 0,34$ & $2,63 \pm 0,48$ \\
\hline $\mathrm{Al}^{3+}\left(\mathrm{Cmol} . \mathrm{C} \cdot \mathrm{dm}^{3}\right)$ & $2,50 \pm 0,66$ & $5,67 \pm 2,00$ & $2,70 \pm 0,62$ \\
\hline $\mathrm{Ca}^{2+}\left(\mathrm{Cmol} \cdot \mathrm{C} \cdot \mathrm{dm}^{3}\right)$ & $0,13 \pm 0,06$ & $3,50 \pm 2,41$ & $0,10 \pm 0,00$ \\
\hline $\mathrm{Mg}^{2+}\left(\mathrm{Cmol} . \mathrm{C} . \mathrm{dm}^{3}\right)$ & $0,10 \pm 0,00$ & $1,70 \pm 1,25$ & $0,10 \pm 0,00$ \\
\hline $\mathrm{K}^{+}\left(\mathrm{Cmol} . \mathrm{C} . \mathrm{dm}^{3}\right)$ & $0,11 \pm 0,01$ & $0,11 \pm 0,01$ & $0,10 \pm 0,02$ \\
\hline
\end{tabular}


Tabela 2. Listagem das espécies encontradas nos três trechos de floresta estudados (A1, A2 e A3) e suas respectivas abundâncias na Estação Ecológica do Tripuí, Ouro Preto, MG.

\begin{tabular}{|c|c|c|c|c|}
\hline Família & Espécie & A1 & $\mathrm{A} 2$ & A3 \\
\hline \multirow[t]{2}{*}{ Anacardiaceae } & Schinus terebinthifolius Raddi & & 12 & \\
\hline & Tapirira obtusa (Benth.) Mitchell & 1 & & \\
\hline \multirow[t]{3}{*}{ Annonaceae } & Guatteria australis A.St.-Hil. & 4 & & \\
\hline & G. sellowiana Schlecht. & 9 & 1 & 12 \\
\hline & G. vilosissima A.St.-Hil. & & & 2 \\
\hline Asteraceae & Eremanthus erythropappus (DC.) MacLeish * & & & 10 \\
\hline Bignoniaceae & Tabebuia heptaphylla (Vell.) Toll. & & 1 & \\
\hline Burseraceae & Protium brasiliense (Spreng.) Engl. & & & 3 \\
\hline Caesalpiniaceae & Sclerolobium denudatum Vog. & 2 & & \\
\hline \multirow[t]{2}{*}{ Celastraceae } & Maytenus alaternoides Reiss. & 1 & & \\
\hline & M. cf. communis Reiss. & 3 & 2 & \\
\hline \multirow[t]{2}{*}{ Euphorbiaceae } & Alchornea triplinervia (Spreng.) Muell. Arg. * & & & 1 \\
\hline & Sapium glandulatum (Vell.) Pax & 4 & & \\
\hline \multirow[t]{5}{*}{ Fabaceae } & Dalbergia foliolosa Benth. & 1 & & 29 \\
\hline & D. frutescens (Vell.) Britt. & 1 & & 2 \\
\hline & Machaerium floridum (Mart. ex Benth.) Ducke & 5 & & \\
\hline & M. nictitans (Vell.) Benth. * & & 5 & \\
\hline & M. villosum Vog. & 3 & & \\
\hline \multirow[t]{5}{*}{ Flacourtiaceae } & Casearia decandra Jacq. * & 7 & 3 & \\
\hline & C. obliqua Spreng. * & & & 1 \\
\hline & C. sylvestris $\mathrm{Sw}$. & 1 & & \\
\hline & Xylosma ciliatifoliun (Clus.) Eich. & & & 1 \\
\hline & $X$. cf. pseudosalzmanii Sleumer & & 1 & \\
\hline \multirow[t]{9}{*}{ Lauraceae } & Endlicheria paniculata (Spreng.) J.Macbr. & & 1 & \\
\hline & Nectandra aff. cissiflora Nees & & 1 & \\
\hline & N. lanceolata Nees et Mart. ex Ness & & 47 & \\
\hline & N. puberula Nees & & & 7 \\
\hline & Ocotea felix Coe-Teix. & & & 2 \\
\hline & O. nitidula (Nees et Mart. ex Nees) Mez & 1 & 3 & \\
\hline & O. aff. puberula (Rich.) Nees & & & 3 \\
\hline & O. pulchella Nees et Mart. ex Nees * & & & 7 \\
\hline & O. cf. spectabilis (Meissn.) Mez & & 1 & \\
\hline \multirow[t]{4}{*}{ Melastomataceae } & Leandra fragilis Cogn. & & & 1 \\
\hline & Miconia chartacea Triana * & & & 9 \\
\hline & M. cf. paniculata Naud. & & & 3 \\
\hline & Tibouchina canescens Cogn. & & & 3 \\
\hline
\end{tabular}


(cont.)

\begin{tabular}{|c|c|c|c|c|}
\hline Família & Espécie & A1 & $\mathrm{A} 2$ & A3 \\
\hline Meliaceae & Cabralea canjerana (Vell.) Mart. * & 1 & & \\
\hline \multirow[t]{2}{*}{ Monimiaceae } & Mollinedia engleriana Perk. & & & 5 \\
\hline & M. schottiana (Spreng.) Perk. & & 1 & \\
\hline Myrsinaceae & Myrsine umbellata Mart. * & 1 & 6 & 3 \\
\hline \multirow[t]{13}{*}{ Myrtaceae } & Calyptranthes cf. clusiifolia (Miq.) Berg. & & & 1 \\
\hline & Eugenia egensis DC. & 6 & 2 & \\
\hline & Eugenia sp. & 9 & & 15 \\
\hline & Gomidesia cf. affinis (Camb.) Legr. & 3 & 18 & \\
\hline & G. cf. palustris (DC.) Legr. & & 1 & \\
\hline & Marlierea cf. parviflora Berg. & 2 & & \\
\hline & Myrcia. crassifolia (Berg.) Kiaersk. & 1 & 5 & 1 \\
\hline & M. rostrata $\mathrm{DC} . *$ & 7 & 18 & 21 \\
\hline & M. cf. linkiana DC. & 9 & & 20 \\
\hline & M. cf. tomentosa (Aubl.) DC. & 1 & & \\
\hline & Myrciaria cf. floribunda (West ex Willd.) Jacq. & & & 4 \\
\hline & Siphoneugena densiflora Berg. & 2 & & 5 \\
\hline & sp.1 & & & 1 \\
\hline Nyctaginaceae & Guapira opposita (Vell.) Reitz & 2 & & \\
\hline Ochnaceae & Ouratea semiserrata (Mart. et Nees) Engl. * & & & 1 \\
\hline Piperaceae & Piper cf. crassinervium H.B.K. & & 1 & \\
\hline Rosaceae & Prunus sellowii Koehne * & 5 & 2 & \\
\hline \multirow[t]{5}{*}{ Rubiaceae } & Alibertia concolor (Cham.) Schum. * & 11 & 21 & 3 \\
\hline & Amaioua intermedia Mart. & 2 & & \\
\hline & Guettarda viburnoides Cham. \& Schlecht. & & 1 & \\
\hline & Psychotria mima Standl. & 2 & & 7 \\
\hline & P. sessilis (Vell.) Muell. Arg. * & 15 & & 24 \\
\hline \multirow[t]{2}{*}{ Solanaceae } & Solanum cladotrichum Dunal & & & 7 \\
\hline & S. pseudoquina A.St.-Hil. & 1 & & \\
\hline Thymelaeaceae & Daphnopsis cf. fasciculata (Meissn.) Nevl. & & 1 & \\
\hline Vochysiaceae & Vochysia tucanorum Mart. & 1 & & \\
\hline
\end{tabular}

* Espécies indicadoras de florestas de altitude do centro-sul do Brasil.

cia Atlântica, devido ao pequeno esforço amostral despendido, sendo necessária a ampliação do número de unidades amostrais para avaliar melhor seu perfil florístico.
Entre as espécies amostradas, ocorreu um pequeno número $(20,6 \%)$ de espécies características das florestas de altitude do sul e sudeste do Brasil (tabela 2). Meira-Neto et al. (1989) indicaram a cota 
de 1000 m como limite para a ocorrência das florestas de altitude do sul e sudeste, entretanto Torres et al. (1997) citam que $750 \mathrm{~m}$ é o limite altitudinal para que sejam observadas diferenças florísticas entre as florestas semidecíduas do interior do estado de São Paulo. $\mathrm{O}$ fato da EET se encontrar em altitudes acima desses limites, pode, a princípio, explicar a ocorrência de espécies de altitude, tais como as citadas por Meira-Neto et al. (1989). Das espécies indicadoras dessas florestas de altitude encontradas por esses autores, observou-se que 11 (26,8\%) ocorrem, também, nos trechos da floresta ora estudada, onde também observou-se Miconia chartacea, Ocotea pulchella e Eremanthus erythropappus, espécies características, mas não exclusivas das florestas semidecíduas montanas do sul de Minas Gerais (Oliveira-Filho \& Machado 1993, Oliveira-Filho et al. 1994).

A maior frequiência de indivíduos nas classes inferiores de PAP (figura 2) é atribuída ao estágio sucessional jovem desses trechos. Verificou-se, também, que a distribuição dos indivíduos entre as classes de PAP, nas áreas 1 e 2, foi significativamente diferente da observada na área 3 (Kolmogorov-Smirnov, p $<0,01$ - tabela 3), contudo não houve diferença significativa entre a distribuição dos indivíduos por classes de PAP das áreas 1 e 2 (KolmogorovSmirnov, $\mathrm{p}>0,05)$. A área 3 não apresentou indivíduos nas classes de PAP superiores a 75,0 cm (figura 2), e observou-se que os indivíduos que apresentaram maiores valores de PAP pertencem à família Melastomataceae, considerada pioneira e característica de locais em estádios iniciais do pro-

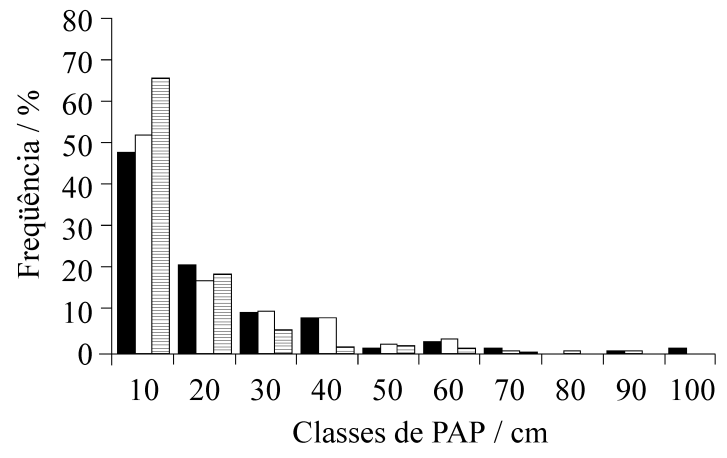

Figura 2. Distribuição das freqüências nas classes de PAP (cm) nos três trechos de floresta estudados na Estação Ecológica do Tripuí, Ouro Preto, MG. Classes de PAP expressas pelo valor central. A1 (口); A2 ( $\square$ ); A3 (目).
Tabela 3. Resultado do teste de Kolmogorov-Smirnov para a comparação entre as classes de altura e de PAP, nos três trechos de floresta estudados (A1, A2 e A3) na Estação Ecológica do Tripuí, Ouro Preto, MG. Os valores acima da diagonal correspondem ao resultado da distribuição de PAP e os valores abaixo da diagonal correspondem ao resultado da distribuição de alturas.

\begin{tabular}{lccc}
\hline & A1 & A2 & A3 \\
\hline A1 & - & 0,204 & $0,008^{*}$ \\
A2 & 0,145 & - & $0,009^{*}$ \\
A3 & $0,001 *$ & $0,005^{*}$ & - \\
\hline
\end{tabular}

* Valores significativamente diferentes ao nível de $1 \%$.

cesso de sucessão (Leitão-Filho et al. 1993), e os indivíduos de Asteraceae (Eremanthus erythropappus - candeia), também característica de áreas sucessionais jovens na região (Pedralli et al. 1997).

Não foi observada a ocorrência de estratos arbóreos definidos nos três trechos estudados, com os indivíduos se distribuindo de forma contínua (figura 3). A distribuição de indivíduos por classes de altura, na área 3, foi significativamente diferente da obtida nos trechos de floresta nas áreas 1 e 2 (Kolmogorov-Smirnov, $\mathrm{p}<0,01$ ), que não diferiram significativamente entre si (tabela 3). Em A3, observou-se maior abundância de indivíduos com altura inferior a 7,5 $\mathrm{m}$ do que nos trechos A1 e A2, além da ausência de indivíduos com altura superior a $12 \mathrm{~m}$. O dossel do trecho A1 da floresta é descontínuo e apresenta uma altura aproximadamente de $12 \mathrm{~m}$, com indivíduos emergentes ( $\geq 16 \mathrm{~m})$. No dossel, as espécies mais comuns foram Dalbergia foliolosa, Machaerium villosum, Rapanea umbellata $\mathrm{e}$ Sclerolobium denudatum e, no subosque, Gomidesia affinis, Guapira opposita, Myrcia tomentosa e Psychotria sessilis. Em A2, o dossel da floresta é descontínuo, também com altura de $12 \mathrm{~m}$, e indivíduos emergentes ( $\geq 15 \mathrm{~m}$ ). No dossel destacaram-se Gomidesia palustris, Mollinedia schotiana, Ocotea spectabilis e Schinus terebinthifolius e, no subosque, Alibertia concolor, Casearia decandra, Daphnopsis fasciculata e Piper crassinervium. Em A3, o dossel é bastante descontínuo e formado por árvores com até $9 \mathrm{~m}$ de altura, destacando-se Alchornea triplinervia, Tibouchina canescens e Eremanthus 


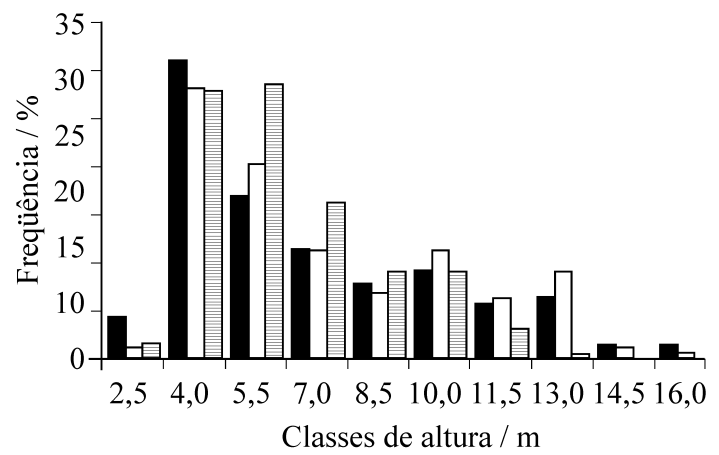

Figura 3. Distribuição das freqüências nas classes das alturas (m) nos três trechos de floresta estudados na Estação Ecológica do Tripuí, Ouro Preto, MG. Classes de

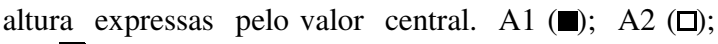
A3 (曰).

erythropappus. No subosque, em A3, identificou-se Guatteria sellowiana, Miconia chartacea, Miconia paniculata e Psychotria sessilis.

O índice de diversidade de Shannon (H'), calculado para os três trechos (tabela 4), ficou abaixo do encontrado para as florestas semidecíduas da região sudeste, que variam de 3,37 a 4,29 nat/ind. (OliveiraFilho 1989). O baixo valor encontrado neste trabalho deveu-se, provavelmente, às diferenças de esforço amostral despendido, visto que H' apresenta limitações relacionadas principalmente, com a intensidade amostral (Cavassan et al. 1984). Os diferentes valores de diâmetro mínimo utilizados nos levantamentos efetuados nas florestas semidecíduas também dificultam as comparações entre os valores de H' (Oliveira-Filho 1989) e, portanto, todas essas comparações devem ser feitas com reserva.

Os valores da equabilidade (J) encontrados (tabela 4) podem ser considerados altos, quando comparados com os estimados para outras florestas semidecíduas do Brasil, que variam de 0,69 e 0,98

Tabela 4. Valores do índice de Shannon e a equabilidade correspondente nos três trechos de floresta estudados (A1, A2 e A3) na Estação Ecológica do Tripuí, Ouro Preto, MG.

\begin{tabular}{lccc}
\hline & A1 & A2 & A3 \\
\hline Índice de Shannon (nat./ind.) & 3,15 & 2,36 & 3,00 \\
Equabilidade & 0,89 & 0,74 & 0,86 \\
\hline
\end{tabular}

(Aragaki 1997). Este índice quantifica a contribuição das populações para a comunidade, em relação ao número de indivíduos (Krebs 1989), possuindo um valor máximo, quando todas as espécies possuem abundâncias iguais na comunidade. Certamente, os valores de $\mathrm{J}$ poderiam ser alterados se fosse aumentada a intensidade amostral nos três trechos. O tamanho da área amostral utilizada provavelmente impediu que as espécies menos abundantes fossem amostradas, não significando, contudo, que tais espécies sejam raras, mas que apresentam poucos indivíduos por unidade de área (Martins 1991, Pagano et al. 1995). O alto valor de $\mathrm{J}$ indica uma baixa dominância por espécie e o critério de inclusão nas áreas amostrais foi o maior responsável pelos resultados obtidos.

A similaridade segundo o índice de Sorensen foi de 37,9\% entre as porções de floresta A 1 e A2, 17,5\% entre A2 e A3, e 35,8\% entre A1 e A3. Baixas similaridades entre áreas de estudo próximas são também mencionadas para florestas semidecíduas de São Paulo, as quais são equivalentes às de florestas situadas em regiões, razoavelmente, distantes ( $\mathrm{Pa}-$ gano et al. 1995).

As diferenças encontradas nos três trechos devem-se principalmente à intensidade de uso ao qual foram submetidos no passado. A floresta, em A3, pode ser realmente considerada um trecho sucessional mais jovem que a de A1 e A2, fato corroborado pelos resultados do teste de Kolmogorov-Smirnov (tabela 3). Além disso, nos trechos A1 e A2, observou-se a presença de Cambissolos, que são solos mais profundos e que permitem o estabelecimento de uma vegetação estruturalmente mais desenvolvida do que nos solos Litólicos, encontrados em A3, que são mais rasos e possuem o substrato constituído por rochas fragmentadas.

Finalmente, levantamentos florísticos e estudos fitossociológicos têm comprovado que fatores ambientais e solos, como nesse estudo, podem ser responsáveis pela variabilidade florística e estrutural entre florestas semidecíduas na região sudeste (Rodrigues et al. 1989, Grombone et al. 1990, OliveiraFilho \& Machado 1993, Oliveira-Filho et al. 1994, Vilela et al. 1994, Gandolfi et al. 1995, Pagano et al. 1995, Araújo \& Haridassan 1997, Araújo et al. 1997). 
Agradecimentos - Ao Biólogo José Aristides Salgado Neto, gerente da Estação Ecológica do Tripuí, e aos demais funcionários da Estação, pelo apoio irrestrito em todas as etapas do projeto; ao Instituto Estadual de Florestas - IEF, por permitir a execução deste trabalho no âmbito da Estação Ecológica; aos curadores dos Herbários SP, SPF, RB, BHCB, GUA e HB pela possibilidade de consulta aos acervos; ao Prof. Dr. José Rubens Pirani (Depto. de Botânica - IBUSP), pela identificação de Rutales; à Bióloga Yule Roberta Ferreira Nunes, pelo auxílio nos trabalhos de campo e à Bióloga Maria do Carmo Brandão Teixeira, pela revisão crítica do texto.

\section{Referências bibliográficas}

ARAGAKI, S. 1997. Florística e estrutura de trecho remanescente de floresta no Planalto Paulistano (SP). Dissertação de mestrado, Universidade de São Paulo, São Paulo.

ARAÚJO, G.M. \& HARIDASSAN, M. 1997. Estrutura fitossociológica de duas matas mesófilas semidecíduas, em Uberlândia, Triângulo Mineiro. Naturalia 22:115-129.

ARAÚJO, G.M., GUIMARÃES, A.J.M. \& NAKAJIMA, J.N. 1997. Fitossociologia de um remanescente de mata mesófila semidecídua urbana, Bosque John Kennedy, Araguari, MG, Brasil. Revista Brasileira de Botânica 20:67-77.

CABRERA, A.L. \& WILLINK, A. 1973. Biogeografia de America Latina. Secretaria General de la Organización de los Estados Americanos, Washington.

CAMARGO, M.N., KANT, E. \& KAUFFMAN, J.H. 1987. Sistema brasileiro de classificação de solos. Boletim Informativo da Sociedade Brasileira de Ciências do Solo 12:11-33.

CAVASSAN, O., CESAR, O. \& MARTINS, F.R. 1984. Fitossociologia da vegetação arbórea da Reserva Estadual de Bauru, Estado de São Paulo. Revista Brasileira de Botânica 7:91-106.

FEAM - Fundação Estadual do Meio Ambiente. 1995. Plano de manejo da Estação Ecológica do Tripuí, Ouro Preto, MG. FEAM, Belo Horizonte, v.1.

GANDOLFI, S., LEITÃO FILHO, H.F. \& BEZERRA, C.L.F. 1995. Levantamento florístico e caráter sucessional das espécies arbustivo-arbóreas de uma floresta mesófila semidecídua no município de Guarulhos, São Paulo. Revista Brasileira de Biologia 55:753-767.

GROMBONE, M.T., BERNACCI, L.C., MEIRA NETO, J.A.A., TAMASHIRO, J.Y. \& LEITÃO-FILHO, H.F. 1990. Estrutura fitossociológica da floresta semidecídua de altitude do Parque Nacional da Grota Funda (Atibaia - Estado de São Paulo). Acta Botânica Brasílica 4:47-64.
IBGE. 1993. Mapa de vegetação do Brasil. Departamento de Cartografia DECAR/DEDIT/CDDI. Escala 1:5.000.000 - IBGE - IBAMA, Rio de Janeiro.

KREBS, C.J. 1989. Ecological methodology. Harper \& Row Publ., New York.

LEITÃO-FILHO, H.F. 1982. Aspectos taxonômicos das florestas do Estado de São Paulo. Silvicultura em São Paulo 16:197-206.

LEITÃO-FILHO, H.F. 1992. A flora arbórea da Serra do Japi. In História natural da Serra do Japi - ecologia e preservação de uma área florestal no sudeste do Brasil (L.P.C. Morellato, org.). EDUNICAMP, Campinas, p.40-62.

LEITÃO-FILHO, H.F., PAGANO, S.N., CESAR, O., TIMONI, J.L. \& RUED, J.J. 1993. Ecologia da Mata Atlântica em Cubatão (SP). EDUNESP/EDUNICAMP, São Paulo.

LEMOS, R.C. \& SANTOS, R.D. 1984. Manual de descrição e coleta de solo no campo. SBCS/SNLCS, Campinas.

MARTINS, F.R. 1991. Estrutura de uma floresta mesófila. EDUNICAMP, Campinas.

MEIRA-NETO, J.A.A., BERNACCI, L.C., GROMBONE, M.T., TAMASHIRO, J.Y. \& LEITÃO-FILHO, H.F. 1989. Composição florística da floresta semidecídua de altitude do Parque Municipal de Grota Funda (Atibaia - São Paulo). Acta Botânica Brasílica 3:51-74.

MORI, S.A., MATTOS SILVA, L.A.. LISBOA, G. \& CORADIN, L. 1989. Manual de manejo do herbário fanerogâmico. CEPLAC, Ilhéus.

MUELLER-DOMBOIS, D. \& ELLENBERG, H. 1974. Aims and methods for vegetation ecology. J. Wiley \& Sons, New York.

OLIVEIRA-FILHO, A.T. 1989. Composição florística e estrutura comunitária da floresta de galeria do córrego da Paciência, Cuiabá, MT. Acta Botânica Brasílica 3:91-112.

OLIVEIRA-FILHO, A.T. \& MACHADO, J.N.M. 1993. Composição florística de uma floresta semidecídua montana, na Serra de São José, Tiradentes, MG. Acta Botânica Brasílica 7:71-88.

OLIVEIRA FILHO, A.T., ALMEIDA, R.J., MELLO, J.M. \& GAVILANES, M.L. 1994. Estrutura fitossociológica e variáveis ambientais em um trecho da mata ciliar do córrego dos Vilas Boas, Reserva Biológica do Poço Bonito, Lavras (MG). Revista Brasileira de Botânica 17:67-85.

PAGANO, S.N., LEITÃO-FILHO, H.F. \& CAVASSAN, O. 1995. Variação temporal da composição florística e estrutura fitossociológica de uma floresta mesófila semidecídua, Rio Claro, Estado de São Paulo. Revista Brasileira de Botânica 55:241-58. 
PEDRALLI, G. \& TEIXEIRA, M.C.B. 1997. Levantamento florístico e principais fisionomias na Estação de Pesquisa e Desenvolvimento Ambiental de Peti, Santa Bárbara, MG, Brasil. Iheringia, Série Botânica 48:15-40.

PEDRALLI, G., FREITAS, V.L.O., MEYER, S.T., TEIXEIRA, M.C.B. \& GONÇALVES, A.P.S. 1997. Levantamento florístico na Estação Ecológica do Tripuí, Ouro Preto, MG. Acta Botânica Brasílica 11:191-213.

PEIXOTO, A.L. \& GENTRY, A. 1990. Diversidade e composição florística da mata de tabuleiro na Reserva Florestal de Linhares (Espírito Santo, Brasil). Revista Brasileira de Botânica 13:19-25.

PINTO, J.R.R. \& OLIVEIRA-FILHO, A.T. 1999. Perfil florístico e estrutura da comunidade arbórea de uma florestas de vale no Parque Nacional da Chapada dos Guimarães, Mato Grosso, Brasil. Revista Brasileira de Botânica 22:53-67.

RIZZINI, C.T. 1997. Tratado de fitogeografia do Brasil. Âmbito Cultural Ed., Rio de Janeiro.
RODRIGUES, R.R., MORELLATO, L.P.C., JOLY, C.A. \& LEITÃO-FILHO, H.F. 1989. Estudo florístico e fitossociológico em um gradiente altitudinal de mata estacional mesófila semidecídua, na Serra do Japi, Jundiaí, SP. Revista Brasileira de Botânica 12:71-84.

SOKAL, R.R. \& ROHLF, F.J. 1979. Biometria: principios y métodos estatísticos en la investigación biológica. H. Blume Ed., Madrid.

TORRES, R.B., MARTINS, F.R. \& KINOSHITA, L.S. 1997. Climate, soils and tree flora relationship in forests in the state of São Paulo, southeastern Brazil. Revista Brasileira de Botânica 20:41-49.

VELOSO, H.P., RANGEL-FILHO, A.L.R. \& LIMA, J.C.A. 1992. Classificação da vegetação brasileira adaptada a um sistema universal. IBGE, Rio de Janeiro.

VILELA, E.A., OLIVEIRA-FILHO, A.T., CARVALHO, D.A. \& GAVILLANES, M.L. 1994. Fitossociologia e fisionomia de mata semidecídua margeando o reservatório de Camargos em Itutinga, Minas Gerais. Ciência e Prática 18:415-24. 